\title{
A contribuição de Amélia Mingas para uma história linguística angolana: contextualizações iniciais
}

\author{
Eduardo Ferreira dos SANTOS D \\ Universidade da Integração Internacional da Lusofonia Afro-Brasileira (UNILAB \\ - IHL/Malês), Universidade de São Paulo (USP - FFLCH/DL/CEDOCH)
}

\section{○ \\ OPEN ACCESS \\ EDITADO POR \\ - Gonçalo Fernandes (UTAD) \\ - Leonardo Ferreira Kaltner (UFF) \\ - Ronaldo Batista (UPM) \\ AVALIADO POR \\ - Regina Helena Pires De Brito \\ (UPM) \\ - Marcelo Rocha Gonçalves \\ (UFMS) \\ DATAS \\ - Recebido: 15/09/2021 \\ - Aceito: 27/09/2021 \\ - Publicado: 07/12/2021 \\ COMO CITAR \\ Santos, E. F. (2021). A \\ contribuição de Amélia Mingas \\ para uma história linguística angolana: contextualizações iniciais. Revista da Abralin, v. 20, n. 3, p. 574-585, 2021.}

\section{RESUMO}

O presente artigo tem como objetivo contextualizar e analisar a produção da linguista angolana Amélia Mingas (1940-2019), em específico seu trabalho Interferência do kimbundu no português falado em Lwanda - 2000 (1988). A partir dessa obra, pretendemos apontar sua contribuição na delimitação de uma história linguística transatlântica subequatorial e descolonizada, nos termos de Negrão (2020) e Coelho; Finbow (2020), contemplando, assim, ecologias ainda pouco privilegiadas em abordagens majoritariamente eurocêntricas. Utilizando-se dos pressupostos teórico-metodológicos da Historiografia Linguística, disciplina responsável pela descrição, análise e interpretação do conhecimento sobre as línguas e a linguagem, produzidos por diferentes agentes e em diferentes intervalos temporais (BATISTA, 2019, p.9), buscamos evidenciar o contexto em que a obra de Mingas foi produzida, isto é, o clima de opinião que permeou o desenvolvimento da obra em questão. Desse modo, valemo-nos das reflexões de Swiggers $(2013,2019)$ sobre os instrumentos conceptuais da Historiografia Linguística, assim como o princípio da contextualização de Koerner (1996, 2014) para alcançarmos nosso objetivo.

\section{ABSTRACT}

This article aims to contextualize and analyze the production of angolan linguist Amélia Mingas (1940-2019), specifically her work Interference of kimbundu in portuguese spoken in Lwanda - 2000 (1988). From this work, we intend to point out its contribution in the delimitation of a 


\section{REVISTA DA ABRALIN}

subequatorial and decolonized transatlantic linguistic history, in the terms of Negrão (2020) and Coelho; Finbow (2020), thus contemplating ecologies that are still underprivileged in mostly eurocentric approaches. Using the theoretical-methodological assumptions of Linguistic Historiography, a discipline responsible for the description, analysis and interpretation of knowledge about languages and language, produced by different agents and at different time intervals (BATISTA, 2019, p.9), we seek to highlight the context in which Mingas' work was produced, that is, the climate of opinion that permeated the development of the work in question. Thus, we used the reflections of Swiggers (2013) on the conceptual instruments of Linguistic Historiography, as well as the principle of contextualization by Koerner $(1996,2014)$ to reach our goal.

\section{PALAVRAS-CHAVE}

Historiografia Linguística. Linguística Angolana. História Transatlântica.

\section{KEYWORDS}

Linguistic Historiography. Angolan Linguistic. Transatlantic History.

\section{Introdução}

Os estudos na área de Historiografia Linguística (doravante, HL), embora diversificados quanto a temática e abordagem escolhidos, ainda são majoritariamente realizados sob uma visão linguística histórica ocidental e sob domínios paradigmáticos tradicionais, em geral, euro-americanos (COELHO; FINBOW, 2020, p.62-63). Assim, é comum nos depararmos com trabalhos que privilegiem, por exemplo, uma gramaticografia ou o pensamento acerca de línguas e linguistas in do-europeus.

Ao fazermos um recorte dos trabalhos da HL sobre a língua portuguesa produzidos até recentemente, notamos que essa trajetória aponta para estudos linguísticos que abordam, em sua quase totalidade, apenas as variedades brasileira e europeia, desconsiderando os demais espaços geopolíticos em que a língua portuguesa se faz presente e, consequentemente, excluindo da agenda uma discussão acerca da formação dessas (novas) variedades nacionais e de todo o pensamento linguístico que emerge nesses espaços.

Se considerarmos os estudos linguísticos no Brasil, por exemplo, percebe-se que, antes pautados e influenciados por uma tradição filológica portuguesa, esses estudos passarão a privilegiar uma abordagem sincrônica na análise linguística e focar nas especificidades do que chamamos de português brasileiro (doravante, PB) (ALTMAN, 2003). Na segunda metade do século XX, como uma forma de compreender as diferenças entre o PB e o português europeu (doravante, PE) que eram atestadas 


\section{REVISTA DA ABRALIN}

pelos estudos sincrônicos então realizados, "uma nova empreitada de estudos diacrônicos foi encaminhada por diferentes percursos e teorias, muitas das quais tinham como questão fundamental o papel que o contato do português com outras línguas - como línguas africanas e indígenas - tivera para a configuração do PB" (SILVA; NEGRÃO, 2018, p.82).

Assim, estudos pioneiros como os de Silva Neto (1950), que abordam o papel do contato linguístico na formação do PB e a discussão sobre o conceito de semicrioulo, importante para sua visão da história do PB (SILVA; NEGRÃO, 2019, p.83), ou estudos como de Mattos e Silva (2008), que apontam os africanos e afrodescendentes como protagonistas na difusão do português no Brasil, indicam um debate ainda profícuo que busca compreender nossa variedade e o pensamento linguístico que perpassa essas questões.

Em relação às variedades de português faladas no continente africano, ainda não temos, em termos quantitativos, estudos como os do PB e PE para os diferentes níveis de análise linguística ou abordagens teóricas. Isso não significa, contudo, que não tenhamos uma eminente, diversificada e fértil produção nos últimos anos, ou que tão pouco tenhamos um pensamento linguístico inexistente, considerando, por exemplo, que são países que passaram por um processo de colonização, como o Brasil, são recém-independentes e apresentam um cenário sociolinguístico atual fruto do intenso contato da língua portuguesa com diferentes línguas autóctones. Esse contato linguístico, mais as questões socio-históricas inerentes a esses países, podem ser as pistas para se entender a formação dessas variedades e suas especificidades em relação ao PB e ao PE.

Deste modo, o foco central deste artigo é apresentar o trabalho Interferência do kimbundu no português falado em Lwanda - 2000 (1988), da linguista angolana Amélia Mingas (1940-2019), e as reflexões ali presentes sobre o português falado em Angola e o papel das línguas autóctones na legitimação de uma nova variedade de português que emerge relacionada aos aspectos histórico, político e social do país.

Assim, vamos considerar sobre o contexto, ou clima de opinião, os termos de Koerner (1996, 2014), em que um pensamento linguístico e, consequentemente o autor e sua obra, não estão isolados, mas, sim, imersos em um quadro de reflexão em relação com outras produções intelectuais. É o que se pode considerar como atmosfera intelectual de um determinado período. Para Koerner (2014, p. 58), "as ideias linguísticas nunca se desenvolveram independentemente de outras correntes intelectuais do período em que surgiram. (...) Por vezes, a influência da situação socioeconómica, e mesmo política, deve igualmente ser tida em conta".

Tomando, então, o contexto presente em Angola à época do desenvolvimento da obra de Mingas, vamos situar a autora nesse cenário linguístico e como esses fatores são colocados em seu trabalho e legitimam sua discussão. Busca-se, portanto, uma forma de contribuir para o debate acerca da construção de um pensamento linguístico que contemple novas ecologias (MUFWENE 2001, 2008), ainda pouco privilegiadas, e somar-se aos trabalhos que buscam articular o desenvolvimento de uma história linguística descolonial, abordando questões relativas aos trânsitos e contatos populacionais que surgem no contexto colonial (NEGRÃO, 2020). 


\section{REVISTA DA ABRALIN}

Para além desta Introdução, na primeira seção faremos uma breve apresentação dos aspectos sociais, históricos e linguísticos da introdução da língua portuguesa em Angola, importantes para se compreender o estatuto do português neste espaço atualmente. Na seção seguinte, Mingas é apresentada ao leitor junto à discussão de sua obra em destaque a partir de sua contextualização. Por fim, apresentamos as considerações finais e as referências bibliográficas.

\section{A língua portuguesa em Angola}

Para que possamos compreender a HL como "a atividade, cientificamente fundamentada, de escrever a história do estudo sobre a linguagem" (SWIGGERS, 2019, p.47) e, no nosso caso, sobre a produção da linguista angolana Amélia Mingas, torna-se necessário destacar, de forma retrospectiva, o eixo temporal da invasão portuguesa ao espaço que hoje conhecemos politicamente como Angola e que se estende até o século XX, em específico à década de 80 e a escrita de Interferência do kimbundu no português falado em Lwanda. Para o nosso relato, é importante apontar os contextos cultural-ideológico, político e (eco)linguístico (SWIGGERS, 2019, p.51) que parecem ser relevantes para o desenvolvimento das argumentações de Mingas sobre a língua portuguesa em Angola, o papel do contato linguístico na formação dessa variedade e da importância de sua legitimação em um contexto pós-colonial.

De acordo com o último Censo (2014) realizado em Angola, as cinco línguas mais faladas no país são o português (71\%), o umbundo (23\%), o quicongo (8\%), o quimbundo (8\%) e o chokwe (7\%). Esses dados, embora apontem um desequilíbrio em termos percentuais, indicam que estamos diante de um país plurilíngue e, portanto, com um cenário sociolinguístico particular em que há a convivência das línguas autóctones mais a língua do colonizador com estatuto de única língua oficial.

Essa predominância da língua portuguesa em termos numéricos deve ser entendida a partir de sua presença no país. O português, em Angola, é introduzido no contexto colonial e das Grandes Navegações iniciados no século XV. Esse processo colonizatório, que se estendeu até meados do século XX, foi um dos fatores que determinou a circulação da língua portuguesa no território, embora sua generalização ocorra entre a população no período pós-independência quando adquire o status de língua oficial (INVERNO, 2008, p. 117), na nova nação.

Anterior a esse processo de oficialização do português como língua no país já independente, vale destacar que o contato linguístico entre a língua portuguesa e as demais línguas autóctones não fez diminuir a veiculação dessas últimas, como atestado por Venâncio (1996, p.51), ao apontar que, entre 1620 e 1750, o quimbundo, por exemplo, é a língua mais usada em Luanda por conta de uma elite afro-portuguesa.

A "africanização" cultural e linguística dessa nova elite afro-portuguesa não é bem vista pelos portugueses da metrópole que começam a impor medidas legislativas para que haja um favorecimento da cultura e línguas portuguesas. Uma dessas medidas é o decreto de 1765 do governador 


\section{REVISTA DA ABRALIN}

Sousa Coutinho que diminuía o uso das línguas africanas para o ensino dos filhos dessa elite portuguesa que passaria a ser ministrado na língua do colonizador (ZAU, 2011, p.94).

No século XIX, podemos destacar o surgimento das estações civilizadoras que para além de funcionarem como uma alternativa para a ocupação territorial, assentavam-se "na presença de missionários religiosos que juntamente com as forças militares e o poder do comércio promoveriam a difusão da língua portuguesa, a moral do trabalho e a religião cristã, em síntese, a civilização" (GONÇALVES, 2018, p.9).

Com a transição da monarquia para o republicanismo, Portugal privilegia o desenvolvimento territorial de suas colônias, fazendo com que um significativo número de portugueses ocupe esses espaços. Agora denominadas Províncias Ultramarinas, os portugueses idealizam um modelo de civilização europeu nessas Províncias que também perpassa pelo domínio da língua do colonizador, ou seja, a língua portuguesa.

Dentre as diversas ações oficiais portuguesas para o domínio da língua, podemos destacar:

i) Decreto $\mathrm{n}^{\circ} 77$ de 9 de dezembro de 1921 - Norton de Matos (Governador Geral e Alto-Comissário de Angola)

Art. $2^{\circ}$ - Não é permitido ensinar, nas escolas das missões, línguas indígenas;

Art. $3^{\circ} \mathrm{O}$ uso das línguas indígenas só é permitido, em linguagem falada, na catequese, e como auxiliar, no período do ensino elementar da Língua Portuguesa.

ii) Estatuto do Indigenato (1954) - Decreto-Lei 39666

Art. $2^{\circ}$ Consideram-se indígenas das referidas províncias os indivíduos de raça negra ou seus descendentes que, tendo nascido ou vivendo habitualmente nelas, não possuam ainda a ilustração e os hábitos individuais e sociais pressupostos para a integral aplicação do direito público e privado dos cidadãos portugueses.

Por essas duas ações, podemos notar que há um total apagamento da heterogeneidade linguística angolana com a anulação das línguas autóctones. Há, portanto, uma ação oficial que predita o português como língua oficial de ensino e uma ação que define os papeis sociais dos angolanos a partir de suas condições de "assimilados" e "indígenas".

Um grupo de assimilados, ou "assimilados ativos", teve um protagonismo na sociedade angolana e no desenrolar do que viria a ser os movimentos de independência do país. Esse grupo apropriouse dos conhecimentos em relação à cultura, ao povo e à história de Angola, em um processo de rompimento das amarras do colonizador e conscientização do povo pela libertação da dominação colonial. Nesse processo, os assimilados utilizavam a língua do colonizador como instrumento de denúncia contra o colonialismo português através de jornais, da literatura militante e revolucionária e atividades políticas (MINGAS, 2000, p.46).

Com a independência angolana, Agostinho Neto, primeiro presidente da nova República, oficializa a língua portuguesa como a língua oficial do país. O português era visto, então, como uma língua 


\section{REVISTA DA ABRALIN}

veicular que permitiria uma unificação nacional em um espaço caracterizado por uma proeminente diversidade linguística. Ressalta-se que a transição de Angola para o português, nos termos de Inverno (2008), como língua oficial não extinguiu as demais línguas, como pudemos notar pelo Censo (2014), e também não foi ignorada pelas instâncias oficiais do país, como percebemos na fala do próprio presidente do país, na ocasião de sua posse, agora como presidente da Fundação da União de Escritores Angolanos, em 1977:

\footnotetext{
O uso exclusivo da língua portuguesa, como língua oficial, veicular e utilizável na nossa literatura, não resolve os nossos problemas. E tanto no ensino primário, como provavelmente no médio será preciso utilizar as nossas línguas. E dada a sua diversidade no País, mais tarde ou mais cedo devemos tender para a aglutinação de alguns dialectos, para facilitar o contacto (INL, 1977, p.7).
}

Se considerarmos a presença da língua portuguesa em Angola, iniciada no contexto colonial e oficializada no país já independente, notamos que, em detrimento de ser uma língua europeia e colonizadora, falada inicialmente por um contingente menor de portugueses, é pelos angolanos que ocorre sua difusão, seja como língua segunda ou língua materna, como se vê atualmente nos levantamentos oficiais do Estado.

Estamos de acordo com Faraco (2016, p.173), portanto, ao constatar que o que ocorre em Angola, e nos demais espaços que passaram pelo processo de colonização e posterior independência, é uma "nativização progressiva das variedades não nativas e sua eventual legitimação como variedade de pleno direito, tornando-se a variedade própria e característica dessas sociedades". Interessa-nos, então, apontar como a legitimação de um "português angolano", ou nativizado, é percebida e apresentada no trabalho de Mingas.

\section{Amélia Mingas e sua contribuição para a história de uma variedade angolana do português}

Amélia Arlete Dias Rodrigues Mingas nasceu em Angola, na cidade de Luanda, em 17 de dezembro de 1940, sendo parte de uma tradicional família angolana com participação nos campos da política, da educação, do desporto e da cultura. Veio a falecer em 12 de agosto de 2019, também em Luanda.

Durante as décadas de 1960/1970, Mingas teve participação ativa na política angolana, sendo filiada ao MPLA (Movimento Popular de Libertação de Angola). Nos anos de 1966 a 1972, por exemplo, Mingas foi coordenadora adjunta da célula do partido em Portugal, sendo responsável pela mobilização de estudantes para integrarem o partido. Participou, também, da Luta de Libertação contra as forças armadas portuguesas que tinha como um dos objetivos a independência angolana.

Em relação a sua vida escolar, cumprindo os estudos primários e secundários em Luanda, Mingas é Licenciada em Filologia Germânica pela Faculdade de Letras da Universidade Clássica de Lisboa, em 1981. Nos anos de 1987 e 1988, recebe o título de maîtrise, respectivamente, em Linguística Geral e Aplicada e 


\section{REVISTA DA ABRALIN}

em Sociolinguística, pela Universidade de Paris V. Seu doutoramento ocorre em 1995, na mesma universidade, sob orientação do professor Emilio Bonvini, ao realizar a descrição da língua iwoyo.

Dentre sua vasta produção científica e participação em eventos acadêmicos, além de trabalhos de direção e administração de órgãos importantes, como o Instituto de Línguas Nacionais, em Angola, ou diretora executiva do Instituto Internacional da Língua Portuguesa, e decana da Universidade Agostinho Neto, vamos privilegiar, conforme já apresentamos, seu trabalho Interferência do kimbundu no português falado em Lwanda.

A referida obra é resultado da tradução de seu trabalho desenvolvido para a obtenção de seu mestrado em Ciências da Linguagem, entre 1987/1988, na Universidade de Paris V, sob supervisão de Louis-Jean Calvet. Embora seja apresentada como uma publicação do ano 2000, tomamos Interferência do kimbundu no português falado em Lwanda como o trabalho "seminal" de Mingas por incluir, já em 1988 (data em que o texto é desenvolvido em francês), alguns indícios de uma percepção de um "português de Angola".

O texto de Mingas, embora produzido na década de 1980, aponta para o que parece ser uma preocupação da autora já nos seus tempos de licenciatura, como mostra uma reportagem de Miguel Gomes (2004):

Do tempo em Portugal, recorda os professores Lindley Cintra (linguística geral) e Ivete Centeno (fonética) e começa a perceber, com a prática diária em Angola e Portugal e com a ajuda da teoria académica, que os angolanos também tinham "uma maneira diferente de estar na língua portuguesa". O conceito tem guiado Amélia Mingas ao longo da trajectória académica, à procura do nosso português, de Angola, e das influências das línguas e culturas locais nestes processos. Ao longo do tempo, e depois de em 1995 se ter doutorado em França (antes concluiu a licenciatura em Lisboa, que tinha ficado para trás devido à situação política do país), tem-se dedicado a entender a especificidade dos falantes de Português em Angola. Para isso é fundamental também conhecer, ao pormenor, as línguas locais angolanas e as suas variantes regionais (GOMES, 2004).

Chama-nos a atenção, a menção aos nomes de dois professores da Universidade de Lisboa. Lindley Cintra e Yvette Centeno. Não tivemos acesso a informações adicionais sobre Yvette Centeno e sua relação com os estudos de Fonética, para além de sua atuação na área de línguas germânicas e seu importante papel como escritora portuguesa, tradutora e autora de teatro, além de ser uma das principais estudiosas de Fernando Pessoa. O nome de Lindley Cintra já é mais familiar no contexto brasileiro e parece-nos ser mais direta sua influência sobre Mingas.

Cintra se doutorou, em 1952, em Filologia Românica, na Universidade de Lisboa, passando a atuar também como docente da mesma universidade. Foi criador do então Departamento de Linguística Geral e Românica e tinha como principais interesses os estudos acerca da literatura medieval, da linguística românica, da dialetologia e da geografia atual da língua portuguesa. Em uma breve biografia de Cintra, Castro (2021) aponta que ao participar das equipes de linguistas responsáveis pela coleta de matérias para o "Atlas Linguístico da Península Ibérica" e percorrer as províncias portuguesas entre 1953 e 1954, Cintra "conheceu o povo".

De imediato, abriram-se-lhe novas janelas de interesse: a dialetologia e a etnografia, disciplinas que desde Leite de Vasconcellos andavam pouco praticadas em Lisboa. Mas não só: como ele próprio 


\section{REVISTA DA ABRALIN}

confessava, a forte experiência humana de abandonar o gabinete e de descobrir como vivia o povo despertou nele a consciência dos problemas sociais e políticos.

Desse modo, dois campos de investigação podem ser depreendidos dos trabalhos de Cintra: i) os estudos sobre as origens da língua portuguesa e ii) os estudos acerca do espaço da língua portuguesa (CASTRO, 2021).

Considerando o fazer científico de Lindley Cintra, Mingas parece ter herdado o interesse de se debruçar sobre os espaços que a língua portuguesa ocupa, como em Angola. Também é importante destacar que o trabalho de Mingas está permeado de práticas de pesquisa de campo, coleta, descrição e análise de dados "do povo".

Após a finalização de sua licenciatura, em 1981, na Universidade de Lisboa, período em que teve contato com Lindley Cintra, Mingas obtém seu segundo título de maîtrise em 1988, agora em Paris. Conforme anunciamos anteriormente, é deste mestrado que temos Interferência do kimbundu no português falado em Lwanda.

Nesta obra, Mingas "tem como objeto uma abordagem descritiva das características de uma variante da língua portuguesa em África, nomeadamente o português falado em Angola, mais precisamente em Lwanda, a capital" (MINGAS, 2000: 15-16). Assim, temos um estudo inédito sobre algumas características do português falado na cidade de Luanda a partir das interferências da língua quimbundo, uma das línguas nacionais de Angola. Mingas, portanto, explicita sua preocupação em apontar para um português específico de Angola e como as línguas e culturas autóctones têm um papel fundamental para a especificidade dessa variedade.

Interferência do kimbundu no português falado em Lwanda é o trabalho mais divulgado de Mingas, por trazer, conforme a própria autora pontua, um distanciamento

\footnotetext{
do grupo de analistas que se caracteriza pela tendência de considerar somente as interferências das línguas dos colonizadores na dos colonizados, ou as influências das línguas de grande difusão nas línguas minoritárias e quase nunca o contrário" (MINGAS, 2000, p.23).
}

Esse distanciamento não é aleatório e nos remete à figura de seu orientador, Calvet, e uma obra seminal publicada por ele em 1974: Linguistique et colonialisme. Petit traité de glossophagie. Em termos gerais, Calvet chama a atenção para o fato de, no colonialismo, haver uma divisão de classes e o impacto que essas divisões terão nas relações de dominações linguísticas, o que o autor chamou de "glotofagia", processo de imposição de uma língua sobre outra. Essa imposição, ou "engolimento", se materializa, por exemplo, através de decretos ou políticas linguísticas. Ressalta-se, assim, que a glotofagia explicita uma relação de desequilíbrio, pois ao se concretizar uma dominação linguística e o consequentemente apagamento de uma língua, interfere-se, também, nos aspectos etnolinguísticos e na ecologia linguística local.

Mingas não estava alheia a essa discussão ao afirmar que há a predominância de uma análise que contempla as influências das línguas de maior alcance em detrimento das línguas minoritárias (MINGAS, 2000, p.23). Ou seja, Mingas tece uma crítica a uma agenda linguística que, embora se debruce sobre o contato linguístico, fenômeno intrínseco em contextos coloniais, ainda recorre a uma visão 


\section{REVISTA DA ABRALIN}

de modelo de descrição e análise em que a língua do colonizador serve de parâmetro. Em Interferência do kimbundu no português falado em Lwanda, Mingas inverte essa lógica, destacando o papel do quimbundo na língua portuguesa falada em Luanda, e como uma forma de mostrar que a língua autóctone pode resistir e sobreviver, não só com seus falantes, mas também nos estudos linguísticos.

Em relação aos aspectos sociolinguísticos - tema do capítulo 3 - a autora introduz o capítulo com uma citação de Labov que afirma ser impossível compreender a progressão da mudança linguística sem levarmos em consideração a comunidade em que se dá essa mudança. Mingas também retoma que estamos diante do contato entre duas sociedades e, consequentemente, dois sistemas linguísticos distintos que "apresentam algumas diferenças linguísticas importantes, que estão na base de muitas alterações morfonológicas e morfossintácticas que caracterizam o português de Angola relativamente ao de Portugal" (MINGAS, 2000, p.43).

Em seguida, a autora descreve a organização social da sociedade colonial e os dois grupos que a formava: os portugueses e os angolanos. Os portugueses se subdividiam em "colonialistas" - agentes da metrópole colonizadora - e em "colonos" - os instrumentos da colonização. Os angolanos se subdividiam em "assimilados" e "indígenas".

Basicamente, os "assimilados" eram um grupo formado por angolanos que tinham direito de fazer com que seus filhos frequentassem a escola com as crianças portuguesas, bem como direito à nacionalidade portuguesa. Os "indígenas" eram os indivíduos de raça negra, e seus descendentes, que nasceram e viviam nas províncias, mas sem a "ilustração e hábitos individuais e sociais" que os qualificavam com os mesmos direitos dos cidadãos portugueses. Para ascender ao status de "assimilados", os "indígenas" realizavam um exame que avaliava, entre diversos aspectos, o domínio da língua portuguesa. Considerando que o ensino não era nem gratuito e nem obrigatório, apenas uma pequena parcela da população angolana teria acesso à educação formal e domínio do português.

Assim, "é muito fácil compreender-se a razão pela qual o português beneficiou do estatuto de "língua de prestígio", relativamente às línguas locais. Este estatuto era um estatuto de facto, pelo que o português tornou-se a língua cada vez mais falada em Angola" (MINGAS, 2000, p.49).

Na conclusão de Interferência do kimbundu no português falado em Lwanda, Mingas discorre sobre a introdução de elementos de uma língua, geralmente a primeira, na segunda língua a ser aprendida em situações de contato. Seja nos termos de Weinreich, para quem a língua aprendida em primeiro lugar resiste melhor a interferência, ou nos termos de Tabouret-Keler, que considera os momentos em que o falante aprende as línguas como determinante para o aparecimento das interferências, para Mingas é evidente que o português foi a língua que mais sofreu interferências em relação ao quimbundo, mesmo esta sendo a língua menos prestigiada e os tipos de relações que caracterizavam a situação colonial (MINGAS, 2000: 91).

Se a política linguística portuguesa se baseou em ações que favoreciam o português como língua de prestígio, como língua a ser difundida e protegida em relação às línguas locais, Mingas pontua que a política angolana abre-se para uma promoção, proteção e difusão das línguas locais, mesmo que a língua portuguesa não tenha sido interditada, sendo colocada como língua oficial no país. Para 


\section{REVISTA DA ABRALIN}

Mingas, esse cenário de convívio do português e das línguas locais é um estímulo para os estudos do contato de línguas em Angola (MINGAS, 2000: 93).

Essa argumentação final de Mingas em relação aos estudos linguísticos e ao estatuto da língua portuguesa e das línguas autóctones em Angola, parece-nos, de fato, só ser possível de ser realizada no período pós-Independência e devido aos fatores político-sociais da época.

No período pós-colonial, Angola assiste a uma criação de condições para que as línguas locais tivessem o mesmo estatuto que a portuguesa. Tem-se, então, o surgimento do Instituto Nacional de Línguas (1979), posteriormente Instituto de Línguas Nacionais - ILN - (1983). Os estudos e levantamentos linguísticos dessa organização foram apreciados pelo governo angolano que atribuiu o estatuto de "línguas nacionais" às línguas africanas faladas no país e o estatuto de "língua oficial" ao português. Um dos papeis do ILN, portanto, é o de difundir e valorizar as línguas nacionais, respaldadas por uma ação política. O trabalho de Mingas não foge desse contexto, ao privilegiar uma abordagem descolonial e tomar uma língua nacional, o quimbundo, como parâmetro de análise em relação à língua do ex-colonizador, o português.

\section{Considerações finais}

Neste trabalho, buscamos apresentar a linguista angolana Amélia Mingas a partir de sua obra Interferência do kimbundu no português falado em Lwanda e apontar algumas de suas reflexões em relação às especificidades sociolinguísticas que permeiam a legitimação de uma variedade angolana do português. Esse exercício mostrou-se necessário por ainda não termos, se comparada ao PB e ao PE, uma sistematização de trabalhos que mostrem a construção desse pensamento linguístico. Desse modo, ratificamos Negrão (2020) da necessidade de uma história linguística descolonial que contemple discussões relativas aos trânsitos e contatos populacionais que surgem no contexto colonial, como é o caso angolano e exposto por Mingas ao longo de sua obra em questão.

Após uma breve apresentação do estatuto da língua portuguesa em Angola, fizemos uma breve análise de como Mingas contextualizava e articulava sua formação acadêmica e a condição política do país em sua argumentação de valorização das línguas autóctones e da legitimidade do português falado em Angola.

Ao inverter uma lógica totalmente colonizadora, que tomava a língua europeia como parâmetro de análise e propulsora de um "engolimento" das demais línguas, Mingas torna-se uma das pioneiras em trazer um olhar descolonial para uma agenda linguística subequatorial e transatlântica ainda em desenvolvimento.

\section{REFERÊNCIAS}

ALTMAN, C. A pesquisa linguística no Brasil (1968-1988). 2.ed. São Paulo: Humanitas/FFLCH/USP, 2003. 


\section{REVISTA DA ABRALIN}

BATISTA, R.O. Historiografia da linguística e um quadro sociorretórico de análise. In: BATISTA, R.O. Historiografia da linguística. São Paulo: Contexto, 2019, p. 81-113.

CASTRO, I. Lindley Cintra. Instituto Camões. c.2021. Disponível em: < http://cvc.instituto-camoes.pt/seculo-

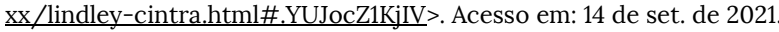

COELHO, O.; FINBOW, T. Apontamentos para uma história linguística transatlântica e descolonizada do português no Brasil: o contato e a diversidade em foco. In: VIEIRA, F.E.; BAGNO, M. (Orgs.). História das línguas, histórias da linguística: homenagem a Carlos Alberto Faraco. São Paulo: Parábola, 2020, p. 61-84.

FARACO, C.A. História sociopolítica da língua portuguesa. São Paulo: Parábola Editorial, 2016.

GOMES, M. Amélia Mingas: uma viagem pelos afectos da linguística. Revista da TAAG, Luanda, n 104 , p. 102-112, Jul/Ago, 2014.

GONÇALVES, P. C. A emigração como força civilizadora: portugueses nas colônias africanas e no Brasil independente. Revista História (São Paulo), n.177, p. 1-53, 2018.

INSTITUTO NACIONAL DE LÍNGUAS. Histórico sobre a Criação dos Alfabetos em Línguas Nacionais. INALD. Departamento de Cultura e Desporto. RPA. Luanda, 1977.

INVERNO, L. A transição de Angola para o português. Uma história sociolinguística. In: SOUSA, J. S. et al. (Orgs.). Comunidades imaginadas: nação e nacionalismos em África. Coimbra: Universidade de Coimbra, 2008, p. 117-129.

KOERNER, K. Questões de persistem em historiografia linguística. Revista da ANPOLL, n. 2, p. 47-70, 1996.

KOERNER, K. Quatro décadas de historiografia linguística: estudos selecionados. Sel. e ed. de textos de R. Kemmler e C. Altman. Vila Real: Centro de Estudos em Letras, Universidade de Trás-os-Montes e Alto Douro, 2014.

MATOS E SILVA, R. V. Ensaios para uma sócio-história do português brasileiro. São Paulo: Parábola, 2008.

MINGAS, A.A. Interferência do kimbundu no português falado em Lwanda. Porto: Campo das Letras, 2000.

MUFWENE, S. The ecology of language Evolution. Cambridge: Cambridge University Press, 2001.

MUFWENE, S. Language Evolution. Contact, competition and change. London \& New York: Bloomsburry, 2008.

NEGRÃO, E.V. (coord). O contato de línguas como base da história linguística transatlântica: multilinguismo, mudança, vitalidade e perigo de extinção de línguas. Projeto de Pesquisa coletivo em elaboração, 2020.

SILVA, W.; NEGRÃO, E. V. Sobre a gênese dos crioulos e a história do português brasileiro: revisitando Serafim da Silva Neto. In: COELHO, O. (Org.). A historiografia linguística no Brasil (1993-2018): memórias, estudos. Campinas: Pontes Editores, 2018, p. 81-101.

SILVA NETO, S. Introdução ao estudo da língua portuguesa no Brasil. 2.ed. Rio de Janeiro: Instituto Nacional do Livro, Ministério da Educação e da Cultura, 1963 [1950].

SWIGGERS, P. A historiografia da linguística: objeto, objetivos, organização. Revista Confluência, n.44/45, p.39$50,2013$. 


\section{REVISTA DA ABRALIN}

SWIGGERS, P. Historiografia da linguística: princípios, perspectivas, problemas. In: BATISTA, R.O. Historiografia da linguística. São Paulo: Contexto, 2019, p. 45-80.

VENÂNCIO, J.C. A economia de Luanda e Hinterland no século XVIII: um estudo de sociologia histórica. Lisboa: Editorial Estampa, 1996.

ZAU, D. A língua portuguesa em Angola. Um contributo para o estudo da sua nacionalização. Tese de Doutorado, Universidade da Beira Interior, 2011. 